\title{
DISCRETE LATTICE ELEMENT APPROACH FOR ROCK FAILURE MODELING
}

\section{Mijo Nikolić}

Scientiffic paper / Znanstveni rad

University of Split, Faculty of Civil Engineering, Architecture and Geodesy, Post.Doc.

Corresponding author: mijo.nikolic@gradst.hr

Adnan Ibrahimbegovic

UT Compiègne/Sorbonne Universités, Lab. Roberval de Mécanique, Centre de Recherches Royallieu, France, Full Professor

\section{Predrag Miščević}

University of Split, Faculty of Civil Engineering, Architecture and Geodesy, Full Professor

\begin{abstract}
This paper presents the 'discrete lattice model', or, simply, the 'lattice model', developed for rock failure modeling. The main difficulties in numerical modeling, namely, those related to complex crack initiations and multiple crack propagations, their coalescence under the influence of natural disorder, and heterogeneities, are overcome using the approach presented in this paper. The lattice model is constructed as an assembly of Timoshenko beams, representing the cohesive links between the grains of the material, which are described by Voronoi polygons. The kinematics of the Timoshenko beams are enhanced by the embedded strong discontinuities in their axial and transversal directions so as to provide failure modes I, II, and III. The model presented is suitable for meso-scale rock simulations. The representative numerical simulations, in both $2 \mathrm{D}$ and $3 \mathrm{D}$ settings, are provided in order to illustrate the model's capabilities.
\end{abstract}

Keywords: discrete model; lattice model; embedded strong discontinuity

\section{DISKRETNI PRISTUP ZA MODELIRANJE SLOMA U STIJENI}

Sažetak: U ovome radu predstavljen je diskretni rešetkasti model razvijen za simuliranje sloma u stijeni. Poteškoće koje se javljaju u numeričkim modelima kontinuuma, kao što su inicijacija pukotine, propagacija više pukotina, njihovo srastanje i utjecaj heterogenosti stijene na mehanizam sloma, uspješno su implementirane u prezentirani model. Model je baziran na Timoshenkovim gredama koje predstavljaju kohezivne veze između zrna stijene koji su modelirani Voronoi ćelijama. Formulacija Timoshenkovih greda je poboljšana ugradnjom jakih diskontinuiteta u uzdužnom i poprečnom smjeru grede za simulaciju sloma zbog otvaranja u vlaku ili klizanja u posmiku. Predstavljeni model je razvijen za simulacije stijene na mezoskali. Numeričke simulacije 2D i 3D uzoraka prikazane su u prezentiranome radu.

Ključne riječi: diskretni model; rešetkasti model; jaki diskontinuitiet 


\section{INTRODUCTION}

Rock is a natural geological composite material composed of grains held together by cohesive forces. The resultant grainy structures in rock can be clearly observed (Figure 1). This configuration often results in rocks having heterogeneities, anisotropies, discontinuities, inelasticity, and commonly, weaknesses and defects. Mechanical failure can be triggered by initial weaknesses, resulting in crack propagations.

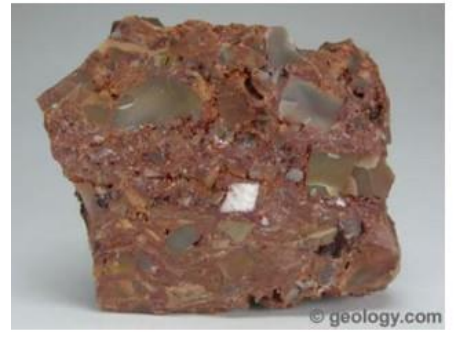

a)

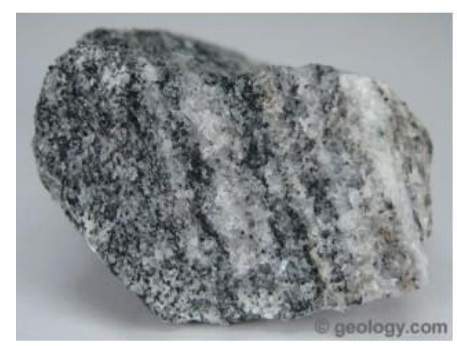

d)

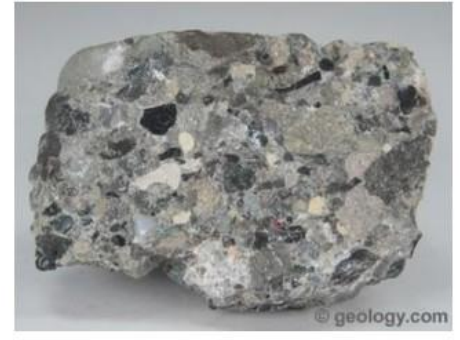

b)

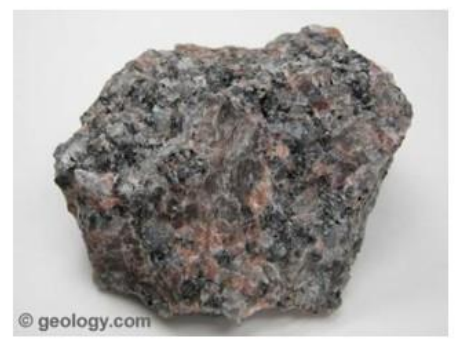

e)

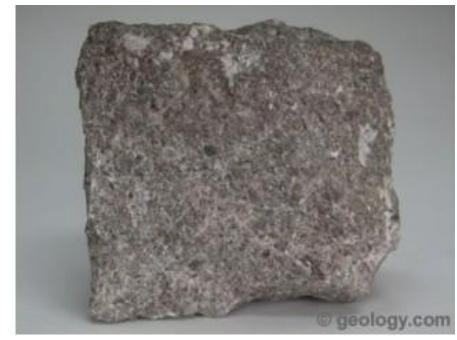

c)

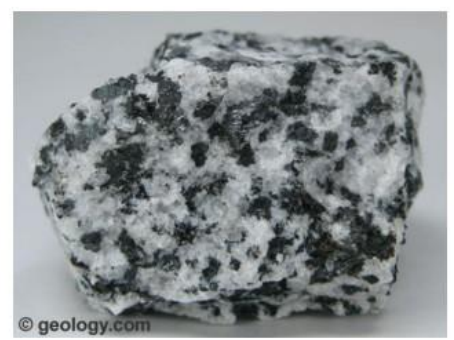

f)

Figure 1 The grainy structure of different rocks: a) Breccia, b) conglomerate, c) limestone, d) gneiss, e) granite, f) quartz-diorite [1]

Failure of this kind of material is clearly complex as it involves crack initiations, multiple crack propagations, coalescence under the influence of natural disorder, and heterogeneities. Providing a numerical solution for localized failure mechanisms with respect to softening, which typically results in a mesh-dependent response, presents additional difficulty. All these aspects are not easily tackled using a continuum of finite elements implemented in finite element method codes [2]. Thus, many different approaches have been developed to deal with the discontinuous nature of rocks. Of these approaches, discrete element models (DEM) [3-5] have been widely used to simulate rock behavior. The combination of finite and discrete element models has proved to be an efficient method for dealing with rock failure and other similar applications [6-7]. A review of different numerical methods for tackling various problems in rock mechanics and rock engineering can be found in the literature [8-9]. Lattice models, as a class of discrete models, can be used to capture important peculiarities in rock failures [10]. A lattice model, constructed from a Delaunay triangulation of the domain where the geometry of the Delaunay edges can be used to define the lattice elements, is presented here. Voronoi cells, as convex polygons, can be derived as a corresponding dual network to the Delaunay triangulation (Figure 2). These polygons represent the grainy structure of the material, along with the corresponding units of the heterogeneous material. The lattice elements, however, are represented by the Timoshenko beams, which act as cohesive links for each grain of rock. Lattice models, typically constructed like this, offer the benefit of incorporating the grainy and discontinuous structure of the material resembling the lattice, considering heterogeneities naturally, and simulating the failure mechanism by reducing the strength of the cohesive links (lattice elements) when a certain failure criterion is reached. All these aspects are important for capturing the effects on a fine meso-scale, to obtain the response at the macro-scale. 


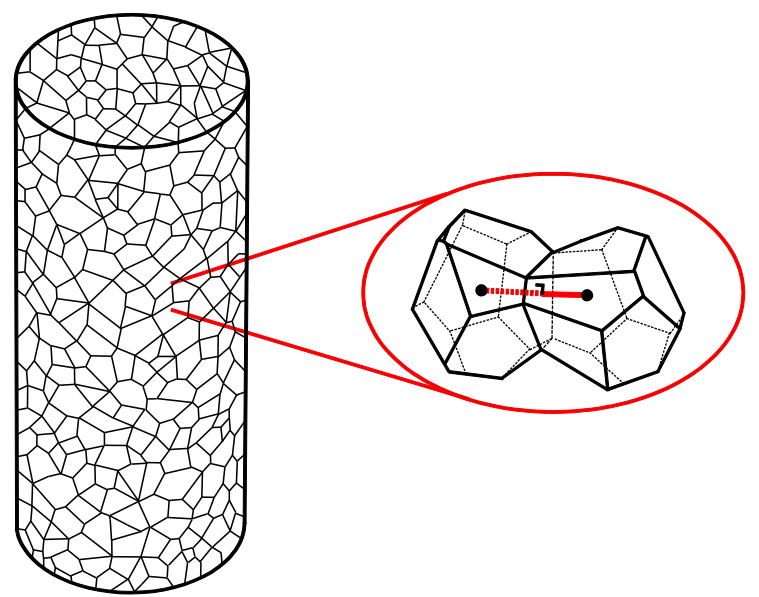

Figure 2 Voronoi polygons derived from Delaunay triangulation. A lattice element keeping together two neighboring Voronoi cells

It is important to properly compute the geometrical and material lattice element parameters that correspond to the material properties of the rock. This means that the geometrical properties of the Timoshenko beams need to be computed, as they provide the correct response for the linear regime, together with the material constants $(E$, v). This is achieved by Voronoi scaling the lattice stiffness terms such that the cross section of each lattice element is computed using two neighboring cells [10].

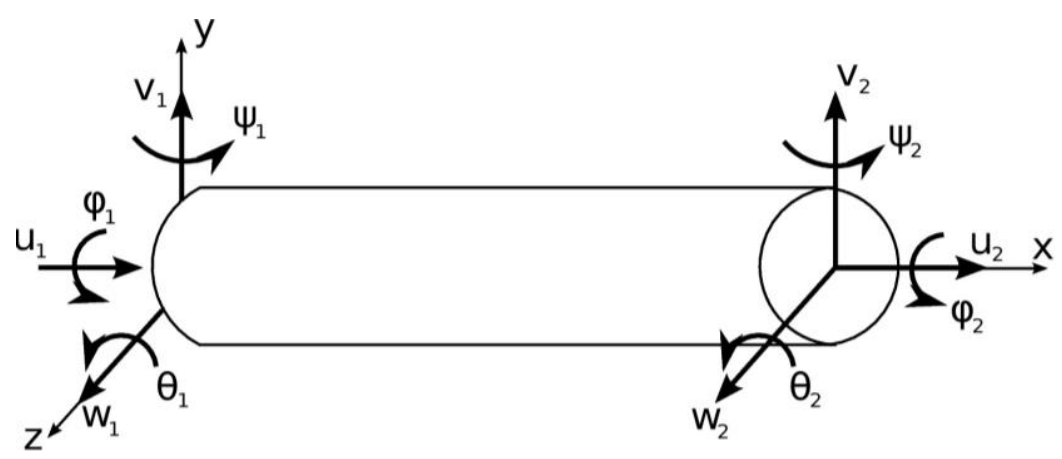

Figure 3 A 3D Timoshenko beam with its degrees of freedom

\section{EMBEDDED STRONG DISCONTINUITIES IN THE LATTICE ELEMENT MODEL}

This paper presents simulations of the $2 \mathrm{D}$ and $3 \mathrm{D}$ versions of the model, while the formulae are provided for the more general $(3 \mathrm{D})$ case. The typical way to simulate crack propagations in lattice models is by checking a certain failure criterion on every lattice element in a mesh; if the criterion is satisfied, the element can soften and its deformation can increase with decreasing stress. Thus, as the grains separate, the Voronoi cells provide the localized failure mechanism. Each lattice element is represented as a single finite element that contributes to the finite element assembly across the whole specimen. However, finite element formulation usually leads to a meshdependent softening response in the localized softening failure regime. One way of stabilizing the localized zone, which leads to a mesh-independent response, is by using embedded strong discontinuities [2] inside the lattice elements [10]. Embedded strong discontinuities offer the benefit of providing the displacement field of the heterogeneities by introducing a displacement jump inside the element, usually represented via the Heaviside function. The formulation of a single lattice element can then begin, with the Timoshenko beam strains given as 


$$
\begin{gathered}
\varepsilon=\frac{d u}{d x} \\
\gamma_{y}=\frac{d v}{d x}-\theta \\
\gamma_{z}=\frac{d w}{d x}+\psi \\
\kappa_{x}=\frac{d \varphi}{d x} \\
\kappa_{y}=\frac{d \psi}{d x} \\
\kappa_{z}=\frac{d \theta}{d x}
\end{gathered}
$$

where the degrees of freedom of each Timoshenko beam are as shown in Figure 3. Here, $\varepsilon, \gamma_{y}, \gamma_{z}$ are the axial strain and two shear strains, respectively. The curvature is denoted by $\kappa_{x}, \kappa_{y}, \kappa_{z}$; displacements by $u, v, w$; and rotations by $\varphi, \psi, \theta$. Introducing embedded strong discontinuities, combined with the Heaviside function, $H_{x_{c}}$, into the beam displacement field results, with an enhanced displacement field, results in

$$
\begin{aligned}
u(x) & =\bar{u}(x)+\alpha_{u} H_{x_{c}} \\
v(x) & =\bar{v}(x)+\alpha_{v} H_{x_{c}} \\
w(x) & =\bar{w}(x)+\alpha_{w} H_{x_{c}} \\
\varphi(x) & =\bar{\varphi}(x) \\
\psi(x) & =\bar{\psi}(x) \\
\theta(x) & =\bar{\theta}(x)
\end{aligned}
$$

where $\bar{u}, \bar{v}, \bar{w}, \bar{\varphi}, \bar{\psi}, \bar{\theta}$ are the standard beam displacements; $\alpha_{u}, \alpha_{v}, \alpha_{w}$ are additional unknowns related to the opening of the discontinuity; and $x_{c}$ is the position of the discontinuity. The enhanced strain fields can be derived from the displacement fields above:

$$
\begin{aligned}
\varepsilon(x) & =\bar{\varepsilon}(x)+\alpha_{u} \delta_{x_{c}} \\
\gamma_{y}(x) & =\overline{\gamma_{y}}(x)+\alpha_{v} \delta_{x_{c}} \\
\gamma_{z}(x) & =\overline{\gamma_{z}}(x)+\alpha_{w} \delta_{x_{c}} \\
\kappa_{x}(x) & =\overline{\kappa_{x}}(x) \\
\kappa_{y}(x) & =\overline{\kappa_{y}}(x) \\
\kappa_{z}(x) & =\overline{\kappa_{z}}(x)
\end{aligned}
$$

where $\delta_{x_{c}}$ is a Dirac delta function, equal to one at the position of the discontinuity and zero outside. Rewriting the equations above leads to the interpolation functions $M(x)$ and $G(x)$, which are used to interpolate the discontinuity in the finite element solution (Figure 4). It can be seen that the embedded strong discontinuity is activated in the longitudinal and transversal directions of the beams, leading to the failure openings in mode I (tensile opening) and mode II (shear sliding), respectively. Additionally, mode III (out-of-plane tearing) is included in the 3D version of the model. The constitutive model, related to the discontinuity, should also be defined. Here, the exponential softening law is used. The computation of discontinuity-related parameters $\alpha_{u}, \alpha_{v}, \alpha_{w}$ is conducted locally with an element-wise approach using a return mapping algorithm. The enhanced weak form can be established from the enhanced strain fields, eventually leading to the formulation of the embedded discontinuity, along with a condensed stiffness matrix and a residual vector that incorporates traction at the discontinuity. 


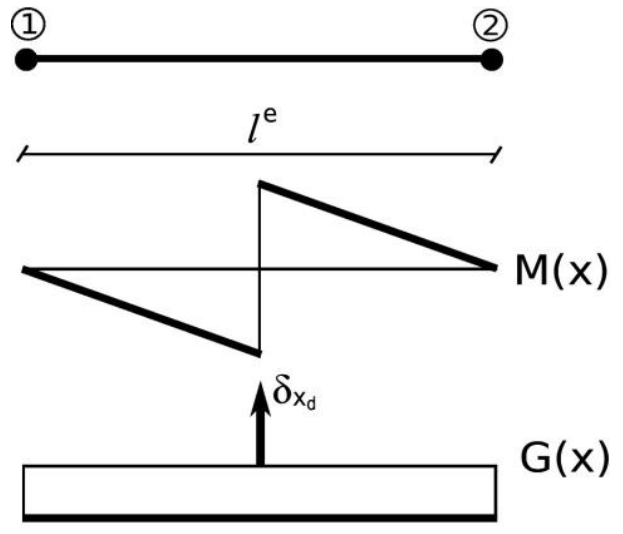

Figure 4 Interpolation functions for the discontinuity

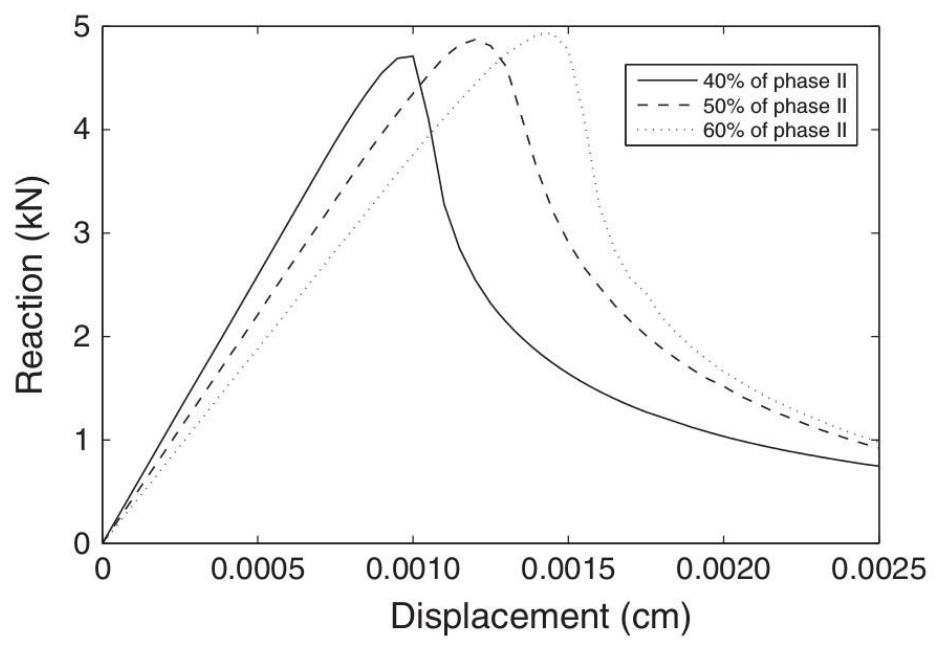

Figure 5 Macroscopic responses for the 2D uniaxial tension test with three different specimens

The full explanation of the 2D and 3D models presented can be found in the literature [11-12]. The presented lattice element model can also be used to solve problems brought about by the failure of fluid-saturated, fractured, poro-plastic materials, using the Biot porous media approach [13], or even to examine the influence of rock specimen shape deviations on uniaxial compressive strength [14].
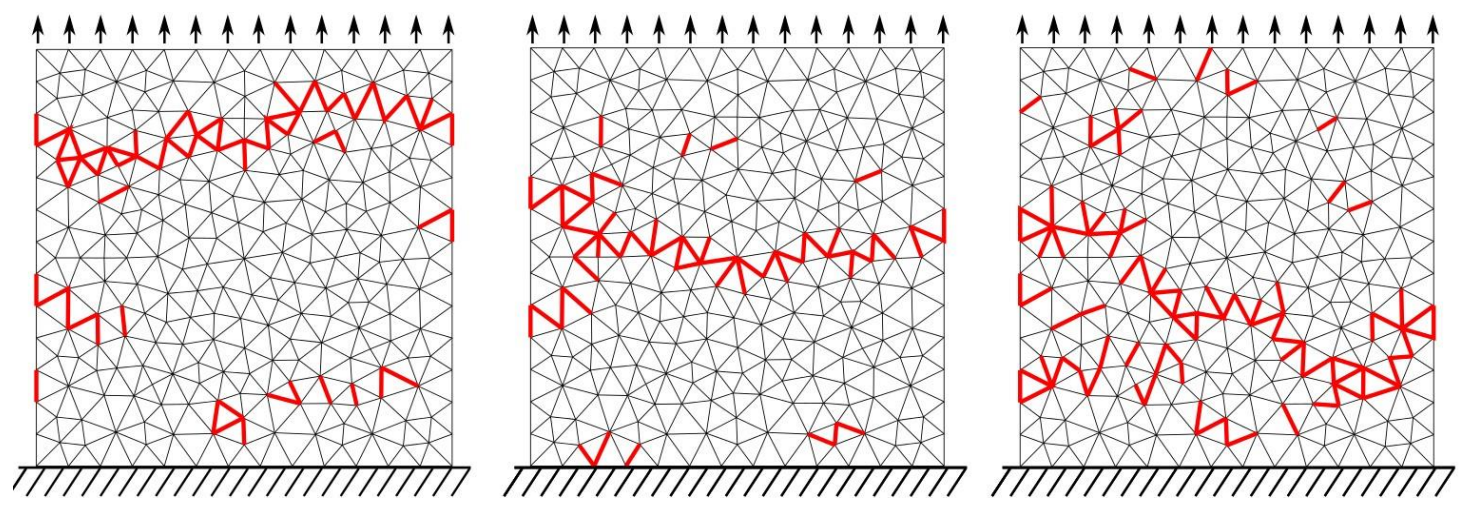

Figure 6 Specimen contours of the uniaxial tension test with three different specimens 


\section{NUMERICAL SIMULATIONS}

The presented model is implemented in the research version of the computer program "FEAP," which was developed at UC Berkeley [15]. This section provides the results of two different numerical simulations, in both $2 D$ and $3 \mathrm{D}$. For the 2D setting, the uniaxial tension test on the 2D Timoshenko beam lattice is chosen to represent the rock specimen [11]. The capabilities of the 3D model are shown using a uniaxial (an unconfined) compression test [12].

The $2 \mathrm{D}$ rock specimens $(10 \times 10 \mathrm{~cm})$ are composed of two phases, where phase I represents the intact rock and phase II represents the weaker parts of the material. The three different heterogeneous specimens are constructed using a different volumetric ratio of phases, while the mechanical characteristics of the two phases are as follows: $\mathrm{E}=70 \mathrm{GPa}, v=0.2$ (phase I); and $\mathrm{E}=10 \mathrm{GPa}, v=0.2, \sigma_{u}=2.2 \mathrm{MPa}, \tau_{u}=1.15 \mathrm{MPa}$, $G_{f, u}=10 \mathrm{~N} / \mathrm{m}, G_{f, v}=1.5 \mathrm{~N} / \mathrm{m}$ (phase II). Here, $\sigma_{u}$ and $\tau_{u}$ are the failure threshold values, and $G_{f, u}$ and $G_{f, v}$ are the fracture energies for tension and shear failure, respectively. Each specimen is tested by imposing the displacement on the upper side of the specimen and monitoring the sum of the reactions, which provide the macroscopic responses (Figure 5). The macroscopic responses show that, with the increase of phase II, the specimen becomes more ductile. The failure patterns in the uniaxial tension test for these specimens are presented in Figure 6, where the broken lattice elements are colored in red, identifying the dominant crack that propagated throughout the specimen. Namely, the stresses in each lattice element are checked against the ultimate values that might lead to the activation of the embedded discontinuity and resultant softening behavior. It is clear from Figure 6 that the failure mechanism is influenced by heterogeneities, leading to a different crack propagation in each specimen.
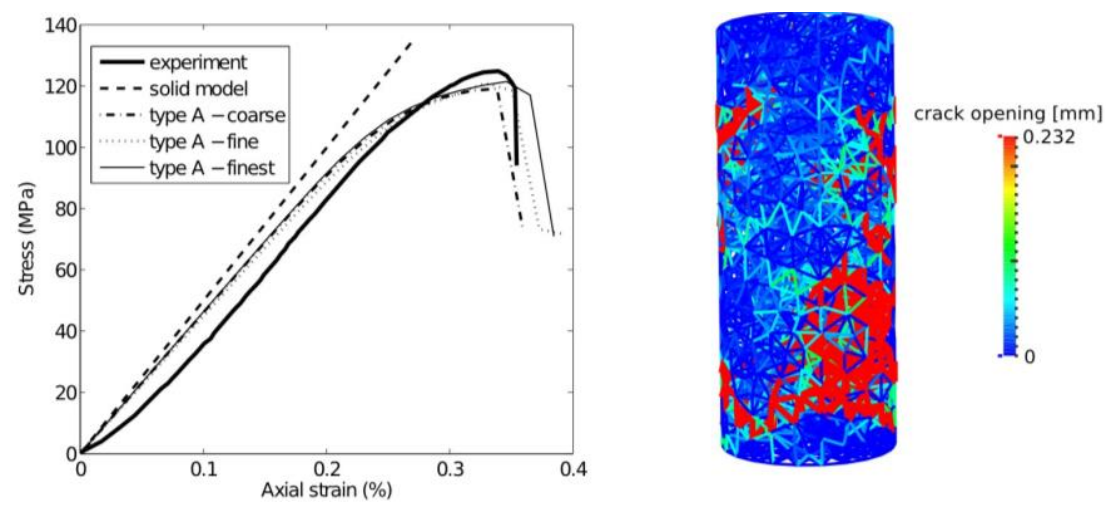

Figure 7 Uniaxial (unconfined) compression test on an intact rock specimen

The uniaxial (unconfined) compression test on a 3D cylindrical limestone specimen with a diameter and height of 5.5 and $13 \mathrm{~cm}$, respectively, is presented next. The specimen is constructed as described in Section 1, using the computed geometric parameters for the lattice elements from the Voronoi polygon. The material characteristics of the lattice elements are given as $\mathrm{E}=50.3 \mathrm{GPa}, v=0.25, \sigma_{u}=12.8 \mathrm{MPa}, \tau_{u}=25.3 \mathrm{MPa}, G_{f, u}=20 \mathrm{~N} /$ $m$, and $G_{f, v, w}=600 \mathrm{~N} / \mathrm{m}$. Heterogeneities are also incorporated into the model, along with the variability of the material failure parameters that obey a Gaussian curve. The upper values are taken as mean values, while the standard deviation is $4 \%$. Additionally, the Mohr-Coulomb law is implemented in the model using a friction coefficient of 0.7. The simulation is conducted using an imposed displacement on the upper side of the specimen, causing a state of compression, and the reaction is monitored. The macroscopic response, shown in Figure 7 , reveals that the failure of the specimen is brittle and that the numerical result closely matches the experimentally obtained limestone curve for a specimen with equal geometric properties [12]. The numerical specimens are also provided as three different versions with respect to mesh size (type A-coarse: 1407 elements, type A-fine: 4398 elements, and type A-finest: 6508 elements). The contour of the lower parts of the broken specimen, where the damage accumulated, is presented in Figure 7. Moreover, failures in modes I, II, and III are also presented. The failure pattern is irregular and depends on introduced heterogeneities. 


\section{CONCLUSIONS}

A discrete lattice element model for $2 \mathrm{D}$ and $3 \mathrm{D}$ rock failure is presented in this paper. The main strength of a lattice model is in the successful representation of the complex failure mechanisms that occur within rock. The insertion of embedded strong discontinuities results in a mesh-independent response of localized failures. The simulation of a uniaxial tension test showed that a dominant crack formed and led to the complete failure of the specimen; however, many more cracks were present in the unconfined compression test, making the failure pattern more complex; namely, all failure modes were present. It is shown that heterogeneities influence the macroscopic responses and failure mechanisms in all cases and that the model is able to predict this nonlinear behavior with respect to these heterogeneities.

\section{References}

[1] Geoscience News and Information. http://geology.com/rocks. Accessed 15 May 2017

[2] Ibrahimbegovic, A. 2009: Nonlinear Solid Mechanics: Theoretical Formulations and Finite Element Solution Methods, 1st edition, Springer, London

[3] Cundall, P.A.; Strack O.D.L. 1979: A discrete numerical model for granular assemblies, Geotechnique, 29, pp. 47-65, https://doi.org/10.1680/geot.1979.29.1.47

[4] Cundall, P.A. 1988: Formulation of a three-dimensional distinct element model-Part I. A scheme to detect and represent contacts in a system composed of many polyhedral blocks, International Journal of Rock Mechanics and Mining Sciences \& Geomechanics Abstracts, 25, pp. 107-116, https://doi.org/10.1016/0148-9062(88)92293-0

[5] Cundall, P.A.; Hart R.D. 1992: Numerical modelling of discontinua, Engineering Computations, 9, pp. 101-113, https://doi.org/10.1108/eb023851

[6] Mahabadi, O.K.; Lisjak, A.; Munjiza, A.; Grasselli, G. 2012: Y-Geo: new combined finite-discrete element numerical code for geomechanical applications, International Journal of Geomechanics, 12, pp. 676-688, https://doi.org/10.1061/(ASCE)GM.1943-5622.0000216

[7] Lisjak, A.; Grasselli, G. 2014: A review of discrete modeling techniques for fracturing processes in discontinuous rock masses, Journal of Rock Mechanics and Geotechnical Engineering, 6, pp. 301-314, https://doi.org/10.1016/i.jrmge.2013.12.007

[8] Ling, J.; Hudson, J.A. 2002: Numerical methods in rock mechanics, International Journal of Rock Mechanics and Mining Sciences, 39, pp. 409-427, https://doi.org/10.1016/S1365-1609(02)00065-5

[9] Ling, J. 2003: A review of techniques, advances and outstanding issues in numerical modelling for rock mechanics and rock engineering, International Journal of Rock Mechanics and Mining Sciences, 40, pp. 283-353, https://doi.org/10.1016/S1365-1609(03)00013-3

[10] Nikolic, M.; Karavelic, E.; Ibrahimbegovic, A.; Miscevic, P. 2017: Lattice element models and their peculiarities, Archives of Computational Methods in Engineering, https://doi.org/10.1007/s11831-017-9210-y

[11] Nikolic, M.; Ibrahimbegovic, A.; Miscevic, P. 2015: Brittle and ductile failure of rocks: embedded discontinuity approach for representing mode I and mode II failure mechanisms, International Journal for Numerical Methods in Engineering, 102, pp. 1507-1526, https://doi.org/10.1002/nme.4866

[12] Nikolic, M.; Ibrahimbegovic, A. 2015: Rock mechanics model capable of representing initial heterogeneities and full set of 3D failure mechanisms, Computer Methods in Applied Mechanics and Engineering, 290, pp. 209-227, https://doi.org/10.1016/i.cma.2015.02.024

[13] Nikolic, M.; Ibrahimbegovic, A.; Miscevic P. 2016: Discrete element model for the analysis of fluid saturated fractured poro-plastic medium based on sharp crack representation with embedded strong discontinuities, Computer Methods in Applied Mechanics and Engineering, 298, pp. 407-427, https://doi.org/10.1016/i.cma.2015.10.009

[14] Stambuk Cvitanovic, N.; Nikolic, M.; Ibrahimbegovic, A. 2015: Influence of specimen shape deviations on uniaxial compressive strength of limestone and similar rocks, International Journal of Rock Mechanics and Mining Sciences, 80, pp. 357-372, https://doi.org/10.1016/j.jijmms.2015.10.008

[15] Taylor, R.L: FEAP. A Finite Element Analysis Program. University of California, Berkeley. http://faculty.ce.berkeley.edu/rlt/. Accessed 15 May 2017 